\title{
Autologous CD8 Positive PBL Sensitized to Drosophila Cell-Presented Melanoma Peptides
}

National Cancer Institute

\section{Source}

National Cancer Institute. Autologous CD8 Positive PBL Sensitized to Drosophila Cell-

Presented Melanoma Peptides. NCI Thesaurus. Code C95715.

A preparation of autologous CD8+ (cytotoxic) human peripheral blood lymphocytes (PBLs) sensitized to Drosophila cell-presented melanoma peptides, with potential immunostimulating and antineoplastic activities. Autologous CD8+ T-lymphocytes, isolated from a melanoma patient, are exposed in vitro to melanoma peptide-pulsed HLA-A2-expressing Drosophila cells, expanded, and reintroduced into the patient; these tumor-reactive $\mathrm{T}$-cells may stimulate a host immune response against tumor cells expressing the melanoma antigens, resulting in tumor cell lysis. Drosophila cells, which do not express any native MHC molecules, have been shown to potently stimulate tumorreactivity in vitro from human peripheral blood lymphocytes $(\mathrm{PBL})$ when stably transfected with human MHC molecules and appropriate adhesion and costimulatory molecules. 